\title{
ON BALANCING THE VALVES OF STEAM ENGINES.
}

That a perfect equilibrium or balanced slide valve for the steam engine is now a desideratum need not be urged, seeing how many plans and schemes have been brought forward from time to time for the accomplishment of that object.

The large $D$ valve as ordinarily adapted to 74 inch cylinders is shown in Figs. 1 and 2, Plate 130, the packing $A$ being introduced at the back of the valve and kept up to it by means of the packing blocks $B$ and the screws C. This arrangement cannot produce an equilibrium of pressure, as the opposite sides of the valve do not at all correspond with each other; and it will be easily seen that in every change in the position of the valve there is also a change in the effect of the pressure, which acts first in one direction and then in another and continually changes in amount. For instance, when the valve is drawn back to admit steam to the cylinder, the full pressure of the steam is directed against that portion of the packing which is directly opposite the port; and when the valve is drawn over and covers the port, that portion of the packing is subjected to the pressure in the cylinder acting against the face of the valve, as in the position shown in the drawing; and when the face of the valve is drawn beyond the packing, then the steam in the steam chest presses the face of the valve against the cylinder, these changes taking place continuously during each stroke of the valve.

The power required to move such valves in large engines, in starting or reversing the engines, is so great that the ordinary mode of handing was seen to be impracticable; it was therefore determined that the power of steam should be employed by attaching a small engine to each set of valves, so that the engineer was only required to move the valve of the small engine, instead of a dozen men or more being necessary to move the great $D$ valve by the ordinary starting handle. But although the power of each of these small engines was equal to a force of upwards of 2 tons acting upon the great $D$ valves, yet when they were fresh packed that power was not sufficient to move them, and in consequence the starting handles could not be entirely dispensed with ; more especially as it was found in practice 
that it was not safe to hand them by these small engines alone, but rather to apply a smaller steam power and make up the deficiency by the men at the starting handle; nevertheless, even with these imperfections, such an arrangement was considered a great improvement.

A parallel equilibrium valve has been substituted by Mr. Wilson of Patricroft to obviate these objections, longitudinal and transverse sections of which are shown in Figs. 3 and 4. The $D$ valve just described is one of a pair, and this is also one of a pair, the steam being admitted either in between the valves or at the outer ends. $D$ is the cylinder face with the port $\mathrm{E}, \mathrm{FF}$ the back balance plate with the balance recess $\mathrm{G}$ opposite the port $\mathrm{E}$. The valve is made with an opening $\mathrm{H}$ through from face to face, for keeping up a communication between the port $\mathrm{E}$ and the recess $\mathrm{G}$ when both are covered by the valve faces, by which means an equal pressure in the recess and the cylinder port is constantly preserved. I I is a packing on both sides of the valve to prevent the steam passing from one end of the valve to the other except by the port and opposite recess; and as the surface on the baek plate is exactly equal to the surface on the cylinder face, and the recess equal to the port, and the opposite sides of the valve equal to each other, as also the packings on each side of the valve, it will be seen that all the opposite surfaces being equal a perfect equilibrium is maintained under any pressure and in all positions.

As this simple form of equilibrium or balanced slide valve overcomes all the difficulties before named, the application of it to marine engines would not only effect a saving of power and a consequent saving of wear and tear of the valves and valve gear, but at the same time the most complete control over even the largest engines would be obtained, and thereby the risk of accident to steam vessels resulting from want of that control would be avoided.

Figs. 5 and 6 show transverse and longitudinal sections of a circular balanced valve on the same principle, applied by Mr. Wilson to winding engines, where perfect control is of so much importance. This valve like the last described has the opposite surfaces equal, and the balance recesses opposite the ports also equal in area to the opposite ports; the valve is slightly tapered in order to obtain a perfect fit in the valve box, and is prevented from jamming by the tempering screw at the back end. The steam 
passes through the casing to both ends of the valve and thence into the interior, through each side of which alternately it is admitted to the ports as in an ordinary short slide; and from the construction of the valve a perfect equilibrium is maintained.

This valve has been also applied to the steam hammer with the most perfect success, as shown in Fig. 13, Plate 132. So light is the friction upon these valves, and equally small the power to move them, that although many of them have been at work upwards of 3 years none of them have shown any tendency to wear after the first few days of being in action, and many of them are working with the same adjustment as at first, not having required any alteration since they were first started. This is much more than was expected, and it was feared that the valve might wear oval if placed horizontal; but on examining several valves after being 2 years at work night and day under a pressure of $60 \mathrm{lbs}$, it was found that the top side of the valve and box was as highly polished as the bottom side, not with a white metallic polish, but black like that of a plate glass mirror; which appears the best proof that no sensible wear was going on, and that the surfaces were really not touching when working, but were kept asunder all round by a thin film of moisture from the steam, acting as a lubrication, preventing contact and thereby preventing wear.

An application of the same principle of valve to locomotive and other engines is shown in Figs. 7 and 8, Plate 131, which are transverse and longitudinal sections of a parallel equilibrium slide valve, with a loose back balance plate, by means of which the valve is allowed to leave the face of the ports when water gets into the cylinder. This valve is the same in principle as the one shown in Figs. 3 and 4, except that it requires no packing. It is equally adapted for two or three ports as the case may be. In this, as in the other valves, the opposite areas are all equal, which is the particular feature of this kind of valve, whereby alone a perfect equilibrium is obtained.

Figs. 9 and 10 are sections of the same valve without the loose plate, the cover of the steam chest then forming the back plate, with surfaces and balance recesses the same as with the loose plate.

Fig. 11 is a section of a duplex valve, to act as an expansion or cut off valve, at the same time serving as an ordinary steam valve, having all the advantages of a broad face for cutting off the steam at an early part of the stroke, whilst the exhaust does not require to be opened or shut any 
sooner than with a valve of ordinary lap. This is effected by the outside frame acting as the cut-off and admission valve, and the inside frame as the exhaust valve ; the outside frame having a longer travel than the inside one, the difference being equal to the difference in the length of the frame.

Fig. 12 is a section of the valve and steam chest of an ordinary locomotive engine; and by comparing this with the other valves it will be seen what a large surface is exposed to the pressure of steam on the one side without an equal counterpoise or balance on the other; this circumstance causes the wear and tear of this kind of valve and valve gear to be very great, and a considerable amount of force is consequently required to keep it in motion, which in some cases is more than one tenth of the whole power of the engine.

Mr. WiLson observed that the principal point in the balancing of the slide valves was that it depended as much on having an equal recess at the back of the valve, corresponding with the opening of the port, as on having equal surfaces for the pressure to act upon in both directions; and that was a point that had not been generally attended to. In the first forms of balanced valve that had been described, when the valve shut over the port, the communication was still kept up between the port and the recess at the back of the valve, so that the valve was always in equilibrium. In the locomotive valve shown, a provision had to be made for the escape of water from the cylinder in case of priming, which was effected by the back plate giving way at the moment to the extra pressure and allowing the valve to rise from the face of the ports like an ordinary slide valve, there being nothing but the steam to keep it down to the face. In the steam hammer the regular self-acting apparatus for moving the valve, although very ingenious, was found objectionable from its great complexity, and the balanced valve that had been described was worked entirely by a simple hand lever; this was now working at the Low Moor Iron Works very satisfactorily, and was found to be of great advantage, giving greater facility for changing the stroke of the hammer, causing no delay in the operation, and saving time with the work. 
Mr. Henry Maudslay was much pleased with the action of the balanced valve in the steam hammer which he had seen at work at Low Moor; it was perfectly easy of management and worked quite efficiently; but it seemed to him that the work would depend on an experienced workman holding the handle, instead of a boy only directing the self-acting gear. In the latter case the boy was only told to wind the handle up or down to regulate the blows of the hammer; but in the other plan the man was required to use his judgment and care in moving the valve exactly to the distance required at each stroke. Supposing a piece of work nnder the hammer nearly finished, only light blows would be wanted, and the self-acting apparatus being once adjusted to give light blows no delay would occur from alteration of the gearing.

Mr. Pilkington had had three hammers working for some time with the balanced valves that had been described, and found their working was quite satisfactory and decidedly preferable to the self-acting gear. The result was that a boy at $10 d$. per day now drove the hammer better than a man at 4s. per day could do previously, since the blows could be so much more readily and quickly varied to suit the work, and lighter and quicker blows given at any time whenever desired without a moment's delay. With the aid of the alteration in the gearing, and the greater space for the work allowed by removal of the former platform required for the man working the gear, he was able to get work under the hammer more than a foot higher than before, and had recently forged under a 30 cwt. hammer a shaft nearly 5 tons weight and 18 feet by $8 \frac{1}{2}$ inches. There was no difficulty in regulating the force of the blow with as great certainty as before, by putting a pin in any required hole of the guide for the hand lever, down to which the lever was pressed at each stroke, giving a constant quantity of steam for each stroke, whilst a lighter blow was given at any moment by stopping the lever short of the pin.

Mr. Morrison said it had been generally considered that self-acting gear was superior for steam hammers, but he had been much pleased with the action of the balanced valve worked by hand, which he had seen at Low Moor; he had since applied a balanced valve of somewhat different construction to his own hammer, and was satisfied that such a mode of working was preferable to self-acting gear. The time lost in screwing. up the gear to adjust it to a different blow was important when a heavy forging was under the hammer, and the constant weekly expense 
of oiling and repairing the self-acting gear made a serious amount; there was also a saving in the cost of wages for working, as he had now only a labourer working the hammer at 16s. per week instead of a man at 24s. per week previously. The hammer could now be worked almost up to the stuffing box, giving a great advantage in getting command of the full length of stroke; he was sure that wherever the balanced valve was adopted, it would be adhered to in preference to self-acting gear.

Mr. WILson observed that the use of the balanced valves in winding engines had been also found a great advantage in economy and convenience; in some cases of large winding engines where he had applied them a saring of $\$ 120$ a year had been found to be effected in each engine, from the greater wear and tear and the greater expense of working the engines with the old valves. Two or three men were required previously to hand the engine with safety, causing increased risk of accident with a deep pit, from the difficulty of managing the engine promptly and readily; but with the balanced valves that was now done with ease by one man.

Mr. Tomuinson asked how it was arranged to make up for the wear of the valve from the back plate, in the case of the locomotive slide valve; there did not appear to be any provision for keeping the back steam tight after wear had taken place.

Mr. WILson replied that he had found the wear was so slight that the elasticity of the plate was sufficient to compensate for it, by the deflection of the plate under the pressure between the supporting sides; for no beam however strong would support a load without bending, and this plate was found to bend sufficiently for the purpose of allowing for the wearing of the surface on which it rested. The back plate was surfaced in a slightly bent position by being cramped into that position while surfacing, and it seemed that then both the valve face and the back plate continued steam tight. The wear of the valve was reduced to a very small amount by balancing the pressure, as it was the pressure only combined with the motion that produced friction; and when the friction was so much reduced, the rubbing surfaces got a fine polished face and continued working for a long time with scarcely any perceptible wear. In the case of vertical valves the wear was still less, the weight of the valve itself being removed. 
Mr. Pilkingron said that at a winding engine working a short pit at Incehall Colliery, the eccentrics had actually been taken off and the engine was worked entirely by hand, having balanced valves working very easily; the engine was thus under the most complete control as to speed, stopping, and starting, and was found to work quite satisfactorily.

The Chairman observed that the general principle of balanced valves was undoubtedly good, and the plan described in the paper seemed a good and successful mode of effecting the object. There were however several cases, such as locomotive engines, where simplicity of construction was of so much importance as to add materially to the difficulty of getting an entirely satisfactory balanced valve.

He proposed a vote of thanks to Mr. Wilson, which was passed.

The following Paper, by Mr. William G. Craig, of Manchester, was then read :- 
BALANCED STEAM VALVES.

Plate 130.

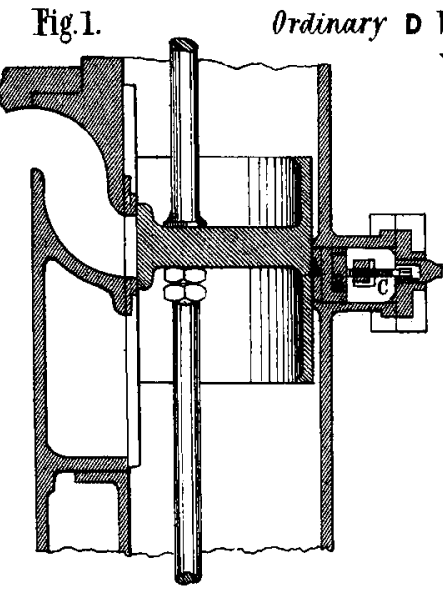

Fig. 2.

Fig. 3. Parallel Balanced Valve. Pig. 4.
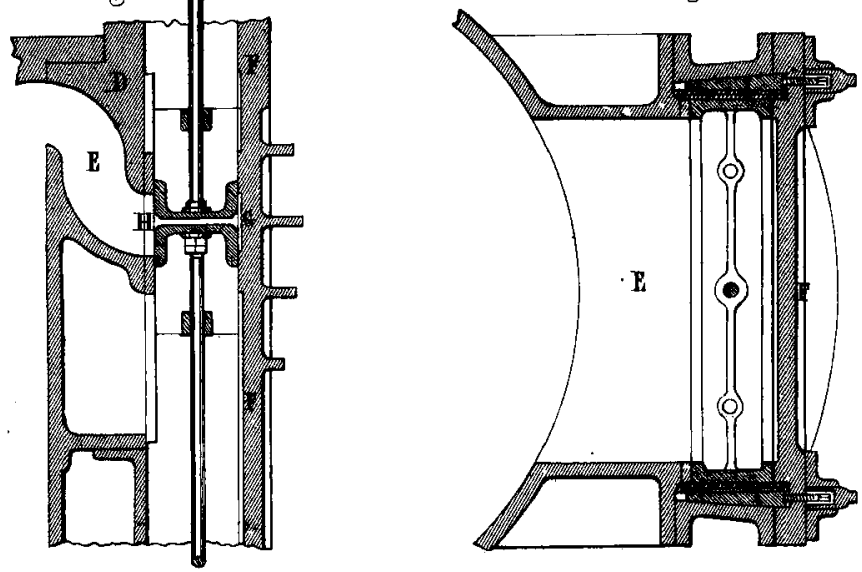

Fig. 5. Circular Balanced Valve Fig. 6.
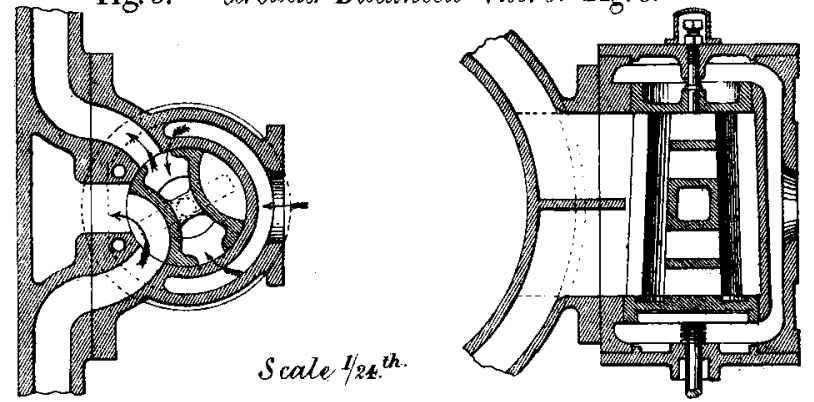

(Proceedings Inst. M.E. 1857 Page 189.) 
BALANCED STEAM VALVES.

Plate 131.
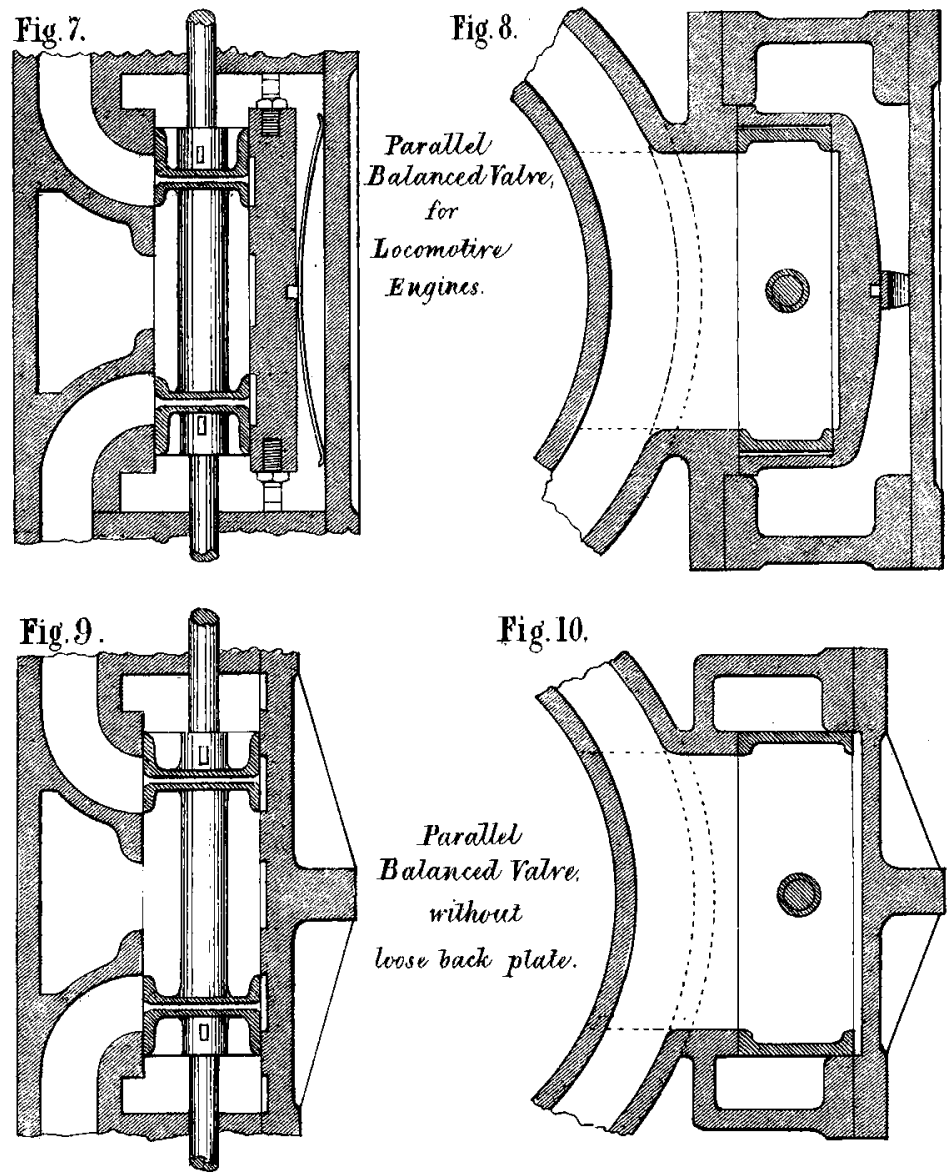

Fig. 10.

\section{Paratlel}

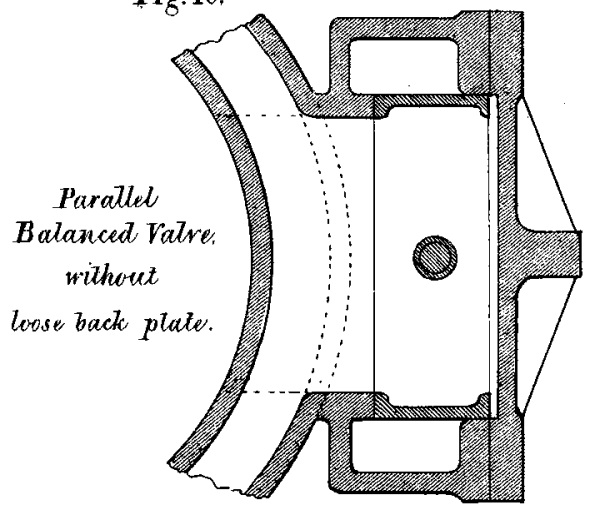

Fig.ll.

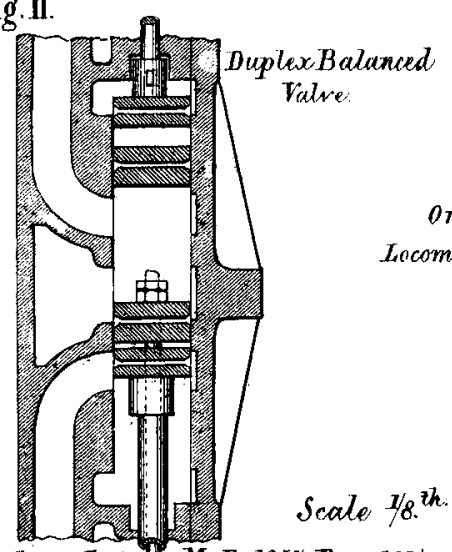

Fig. 12.

ordinary

loose back plate.

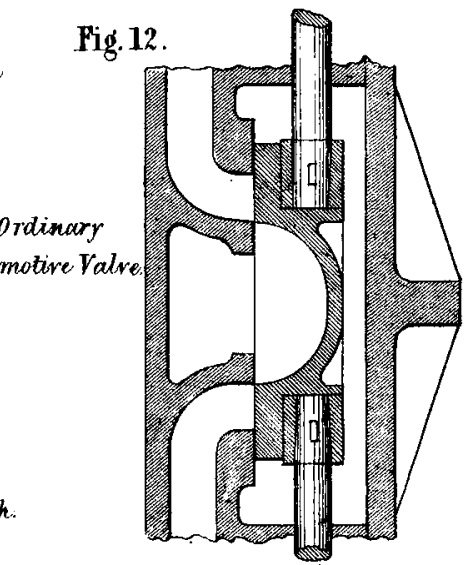

(Proceedings Inst W. M.E. 1857. Page 191.) 
BALANCED STEAM VALVES.

Fig. 13.

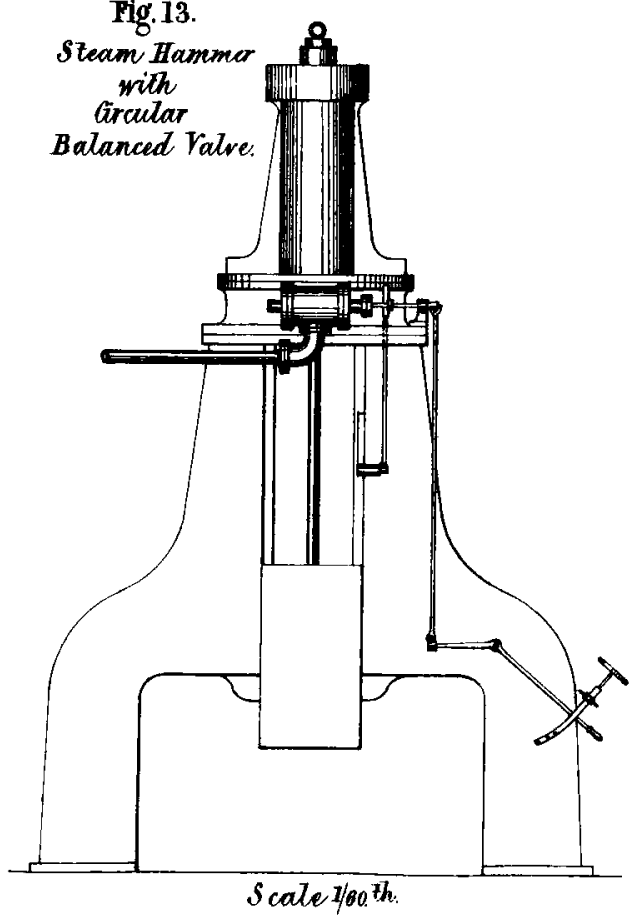

SAFETY ESCAPE PIPE.

Plate 132

Fig. 2. Longitudinat Section of Safety Bscape Pipe entarged.

Fig. 2. Longitudinat section of Safety is cappe Pipe entarged

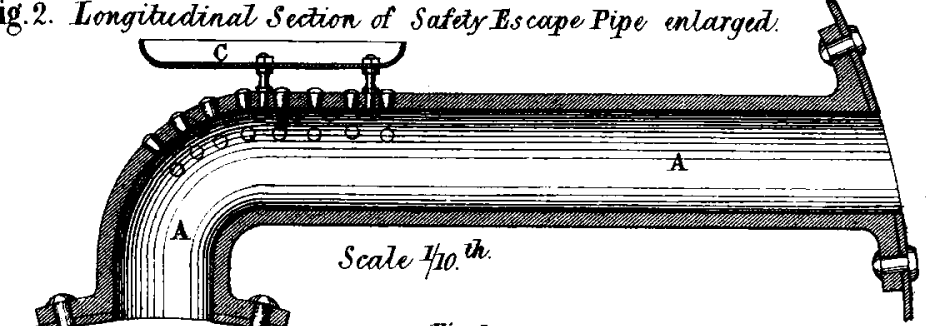

Fig. 3. Cylindrical Boiler with internal fireplace.

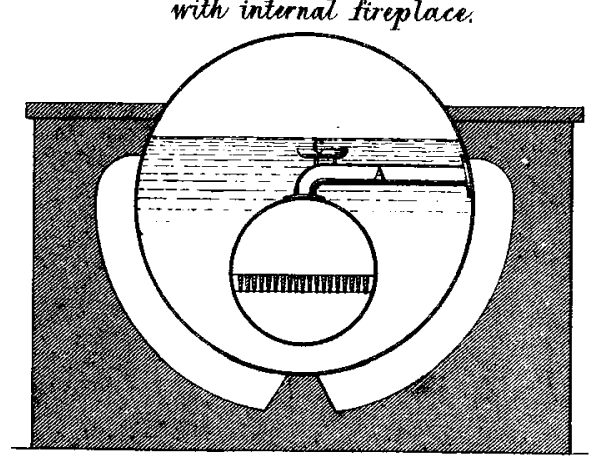

Fig. 1. Transverse

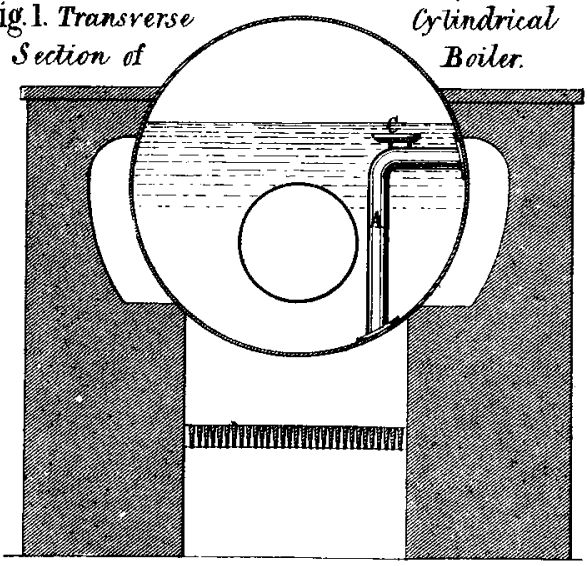

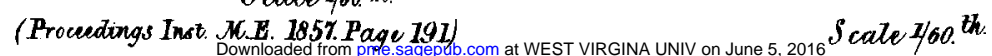
$\begin{array}{lllllllllll}0 & 1 & 2 & 3 & 4 & 5 & 6 & 7 & 8 & 9 & 10 \text { Feet }\end{array}$ 